\title{
The Omega Project: An Empirical Study of the NDE-Prone Personality
}

\author{
Kenneth Ring, Ph.D. \\ University of Connecticut
}

Christopher J. Rosing, B.S.
Dauphin County Area Agency on Aging

ABSTRACT: Seventy-four near-death experiencers (NDErs) and 54 persons interested in near-death experiences (NDEs) participated in a mail questionnaire survey to assess the role of psychological factors in influencing susceptibility to NDEs and to measure aftereffects stemming from such events. NDErs, while not more fantasy-prone than control subjects, reported greater sensitivity to nonordinary realities as children and a higher incidence of child abuse and trauma. NDErs also scored higher on a measure of psychological dissociation. We discuss the implications of these findings for the concept of an NDE-prone personality. In addition to substantial shifts in values and beliefs, NDErs described far more psychophysical changes, including symptoms of kundalini activation, following their NDEs than did controls. We then discuss the implications of these findings with respect to their possible significance for human transformation and the emergence of a more highly evolved human being, the Omega Prototype.

Despite a decade and a half of research on near-death experiences (NDEs), we still know surprisingly little about the psychological makeup of individuals who report these encounters. Of course, we have long been aware that such demographic factors as race, gender, social

Dr. Ring is Professor of Psychology at the University of Connecticut in Storrs, CT. At the time of this study, Mr. Rosing was a student at the University of Connecticut; he is currently Care Manager at the Dauphin County Area Agency on Aging in Harrisburg, PA. Reprint requests should be addressed to Dr. Ring at the Department of Psychology, U-20, Room 107, University of Connecticut, 406 Babbidge Road, Storrs, CT 06269. 
class, educational level, and age are virtually uncorrelated with NDE status (Ring, 1980; Sabom, 1982; Gallup, 1982; Bush, 1983; Morse, Castillo, Venecia, Milstein, and Tyler, 1986).

Likewise, religious orientation and affiliation, though they may influence the interpretation of the experience, seem to play a negligible role in affecting the likelihood of reporting an NDE (Osis and Haraldsson, 1977; Ring, 1980; Sabom, 1982; Gallup, 1982; Grey, 1985). Similarly, prior knowledge about NDEs has been shown not to improve one's chances of actually experiencing one (Ring, 1980, Sabom, 1982). From such findings, the NDE, at least at a sociological level, appears to "play no favorites," and gives the impression of being a randomly occurring phenomenon.

But what about the psychological level? Is it really plausible that here, too, the NDE is a random variable? Or might it be that there are, after all, some distinctive psychological factors that predispose certain people more than others to have, or remember having had, NDEs?

For instance, in the early 1980s, Sheryl C. Wilson and Theodore X. Barber (1983), in their initial work on the fantasy-prone personality, suggested that NDErs might come disproportionately from these ranks; that is, that NDErs would be persons who are especially likely to have a facility for entering into a state of rapt immersion in a world of self-created fantasy. A couple of years later, James Council and Bruce Greyson (1985) showed in a preliminary study, which was never published, that a sample of NDErs did indeed score higher on a measure of fantasy-proneness than did control groups made up of individuals who had been close to death but didn't recall an NDE and individuals interested in NDEs who had never been near death. In addition, Council and Greyson found that NDErs also scored higher on an instrument measuring psychological absorption-the tendency to become deeply involved in sensory and imaginative experiences-than did the control groups.

Taking a cue from these investigators, we thought it would be worthwhile to reopen the issue of whether such factors as fantasy-proneness might serve as predisposing psychological tendencies that would increase the probability of NDE reports and, if so, would therefore predict who would be likely to remember such experiences in the first place. A primary purpose of the study to be reported in this article, then, is to assess through empirical investigation the possible relevance of a number of psychological factors to the likelihood of reporting an NDE following a near-death incident. As implied, fantasyproneness isn't the only possible predisposing variable to be examined in this study. Let us now, therefore, review some of our other candidates. 
Clearly, one possible characteristic that might sensitize individuals to NDEs is the ability to respond to paranormal experiences in general. We know, of course, that NDEs appear to stimulate the development of psychic awareness (Greyson, 1983; Kohr, 1983; Ring, 1984; Grey, 1985; Atwater, 1988; Sutherland, 1990), but whether NDErs are psychically inclined to begin with has remained unclear (Kohr, 1983; Sutherland, 1990). Accordingly, one of the aims of the Omega Project is to assess the degree to which NDErs were, as children, already more open to the realm of paranormal experiences.

Quite apart from psychic sensitivities per se, there is also the question whether NDErs are, as commentators such as Hilary Evans (1989) and Kenneth Ring (in press) have proposed, especially susceptible to altered states of consciousness that would, in turn, disclose what have been called nonordinary realities. If NDEs are held to be embedded in such a domain, those persons who are particularly gifted at entering into states of consciousness that afford perceptual access to that domain would obviously be most likely to report awareness of NDEs. Therefore, another objective of our study is to determine the extent to which NDErs were, again as children, sensitive to what we will simply call for now alternate realities.

One factor that might theoretically account for such sensitivity, if indeed it proves to be characteristic of NDErs, is dissociation, a form of psychological fragmentation in which one portion of the individual splits off, like an autonomous entity, from the conscious self. Since some theorists, such as Evans, hold that dissociation is the key that in effect unlocks the door into alternate realities, it is important to determine whether NDErs are especially prone to dissociation, so that, too, will be examined in this study.

It may, however, be asked why one should think that dissociation might be a part of the psychological profile of NDErs in the first place. The answer lies in the fact that one of the most common antecedents to dissociation, which is widely held to be a defensive reaction to stress, is childhood abuse and trauma. There is some preliminary but mostly anecdotal evidence (Stewart and Carrione, 1987; Barbara Harris, personal communication, 1987; Ellen Stoia, personal communication, 1987) that NDErs may be more likely than others to suffer such a childhood history which, because it tends to foster a dissociative defense style (Kluft, 1985; Sanders, McRoberts and Tollefson, 1989), may facilitate the occurrence and recall of an NDE in later life. In any case, the possible link between child abuse and trauma, on the one hand, and NDEs, on the other, has never been carefully researched; this study represents the first such effort to see whether such a connection does indeed exist. 
These, then, are some of the psychological characteristics that are of focal concern to us here. However, they constitute only one aspect of the attempt to delineate a psychological profile of NDErs.

Quite apart from factors that may predispose persons to remember and report NDErs, we are also concerned here with a wide range of aftereffects that appear to emerge following these experiences. Needless to say, there has already been a fair amount of research documenting some of the aftereffects of NDEs (Ring, 1984; Grey, 1985; Flynn, 1986; Atwater, 1988; Pennachio, 1988; Sutherland, 1990), but much of it has suffered from a lack of statistical rigor. The Omega Project, in consequence, was designed to provide a more solid statistical basis for assessing NDE aftereffects. Our hope here, however, was not merely to replicate previous findings but also to examine a wider spectrum of aftereffects than has heretofore received careful attention. So, for example, in addition to probing how NDEs affect personal values, we also provide a measure of the extent to which there are subjective psychophysical changes following NDEs. Of special interest in this context are our data on kundalini activation in the aftermath of NDEs, a matter about which there had been only some tantalizing but mostly anecdotal or impressionistic findings until now (Ring, 1984; Greyson, 1990). This study also includes an opinion inventory that permits us to see how NDEs affect beliefs and worldviews, especially those having to do with the possible evolutionary significance of these encounters. By these various measures, then, the Omega Project will provide a psychological portrait of the NDEr in terms of aftereffects as well as antecedents.

To sum up the purpose of the Omega Project, we may say that all the specific objectives of our study reviewed in this introduction reduce to two general ones:

1. to assess some possible developmental and psychological characteristics that may be associated with individuals reporting NDEs and that may serve to define the NDE-prone personality, and

2. to assess some of the aftereffects of NDEs.

\section{Method}

\section{Sample}

One hundred and twenty-eight persons participated in this study. Demographically, the sample was overwhelmingly Caucasian, well educated (more than $80 \%$ had at least attended college), with an aver- 
age age in the mid-to-late forties. Our respondents were drawn from two sources: from letters in the archives of the senior author, and from those of the International Association for Near-Death Studies. None of the participants had been involved in any of the authors' previous near-death research.

\section{Design}

The sample was divided into two groups designated and comprised as follows: (a) NDE = persons who reported having had an $\operatorname{NDE}(n=74)$; and (b) NDC = persons who were interested in NDEs, but never had one themselves $(n=54)$. The NDE sample will hereafter also be referred to as our experiential group, whereas the NDC sample will be called our control group.

A superior control group, of course, would have consisted of persons who were known to have been close to death but who did not recall having had an NDE. Such a group, however, is rather more difficult to constitute than one of interest-only respondents, which will serve our purposes adequately here. Not only convenience but empirical evidence also supports the use of an interest-only control group: Council and Greyson (1985) found such persons scored about the same on measures of fantasy-proneness and psychological absorption as did those who had survived a near-death incident without recalling an NDE, suggesting that these two categories of persons may be psychologically comparable.

\section{Instruments}

The data from this study derive from seven specially designed or adapted questionnaires that together with two background information forms comprise the Omega Project Battery. All nine instruments were contained in a single booklet for ease of administration. A brief description of each instrument listed in the order in which they appeared in the battery follows:

1. Background Information Sheet: requests basic demographic information.

2. Experience and Interest Inventory: determines NDE experiential and interest history; used for final assignment to experiential or control group. 
3. Childhood Experience Inventory: assesses the incidence of unusual psychological and paranormal experiences in childhood (29 items).

4. Home Environment Inventory: solicits information on factors related to child abuse and other childhood traumata (38 items).

5. Psychological Inventory: provides a measure of tendencies toward psychological dissociation (40 items).

6. Psychophysical Changes Inventory: covers a wide range of psychophysical changes (60 items).

7. Life Changes Inventory: assesses changes in personal values and interests (50 items).

8. Religious Beliefs Inventory: provides an overall measure of the extent to which respondents shift toward a generalized universalistic spiritual (rather than a sectarian religious) perspective (12 items).

9. Opinion Inventory: assesses respondents' understanding of their experience (or interest) and its impact on their beliefs and opinions.

Instruments 6,7 , and 9 exist in two slightly different forms, one for the experiential group and the other for the control group.

\section{Procedure}

Potential respondents were sent a letter from the first author briefly describing the Omega Project and inviting them to participate in it. No remuneration was offered for this participation; instead a summary of the major findings of the study was promised and sent at the conclusion of the study. Accompanying the letter of invitation was a reply postcard with blanks for respondents to indicate (1) their willingness to take part in the study and (2) their NDE status (i.e., either experiencer or not).

Once their postcard was received, respondents were sent an Omega Project Battery along with a detailed letter instructing them how the battery was to be filled out. An informed consent sheet was also enclosed and required to be signed to permit participation. After all the forms were completed, respondents were asked to enclose them in an already stamped and addressed envelope and mail them back to the senior author. Upon receipt of the battery, respondents received a card acknowledging its arrival, thanking them again for their participa- 
tion, and promising them a summary of the findings at the conclusion of the study.

Each respondent's data packet was inspected to insure its completeness and the Experience and Interest Inventory was checked to make certain the respondent was entitled to be assigned to an appropriate group. The batteries of all eligible respondents were then placed in folders and filed until the data entry and analysis phase of the study.

\section{Results}

\section{Psychological and Developmental Factors}

In presenting a systematic account of our findings, it will be convenient to consider our data in relation to each of the seven principal questionnaires in the Omega Project Battery in the order of their occurrence.

Childhood Experience Inventory (CEI). This questionnaire provided measures of three psychological factors that could possibly sensitize persons to the existence of anomalous phenomena such as NDEs that may be said to have their locus outside of the normal range of ordinary sensory-based waking consciousness. The first of these factors is fantasy-proneness, whose influence in shaping such perceptions was assessed by a ten-item scale embedded in the CEI. Three items from this scale will suggest its nature:

"As a child, I had a very vivid imagination."
"When I was young, I daydreamed a lot."
"As a child, my fantasy world was very rich."

If fantasy-proneness is a factor that increases the likelihood of reports of NDEs, we should find our experiential respondents scoring higher than their controls on this factor. The results are shown in Table 1.

Inspection of this table makes it clear that fantasy-proneness, in contrast to the findings of Council and Greyson (1985), is not a factor that differentiates our experiential from our control group. Indeed, the mean score on this measure is nearly identical for the two groups. Accordingly, there is no evidence from our study that NDErs are distinctively characterized by tendencies toward fantasy-proneness. 
Table 1 Means for Selected Scales of Childhood Experience Inventory

\begin{tabular}{lccr}
\hline & $N D E(n=74)$ & $N D C(n=54)$ & \multicolumn{1}{c}{$p^{*}$} \\
\hline Fantasy-proneness & 5.79 & 5.71 & n.s.** \\
Alternate realities & 1.66 & 0.67 & .004 \\
Psychic sensitivities & 2.01 & 0.91 & $<.001$ \\
\hline
\end{tabular}

*p value based on $t$ test

**n.s. $=$ not significant

Our failure to replicate Council and Greyson's findings here may be attributable to the fact that our measures of fantasy-proneness were not comparable. Council and Greyson employed a heterogeneous instrument that, besides tapping fantasy-process, assessed such features as belief and interest in altered states of consciousness and paranormal phenomena. Our scale, on the other hand, was designed to provide an index of tendencies toward fantasy-proneness only. We need more information on the psychometric properties of these questionnaires before we can resolve the discrepancy.

Although fantasy-proneness was not a feature of the psychological makeup of our experiential sample, other traits most definitely were. For example, another of our measures derived from the CEI dealt with the extent to which our respondents had as children been sensitive to what we have called alternate realities. Again, a couple of statements from this eight-item scale will give its flavor and also suggest how it differed from that concerned with fantasy-proneness.

"As a child, I was aware of non-physical beings while I was awake."

"As a child, I was able to see into other realities that others didn't seem to be aware of."

The second row of Table 1 shows a very different outcome here than that found for fantasy-proneness. A $t$ test on these scores shows that there is in fact a significant statistical effect here $(p=.004)$, indicating that NDEr respondents are more likely than controls to affirm that as children they were already sensitive to alternate realities.

As can also be seen from Table 1, precisely the same differential is found for reported incidence of childhood psychic experiences, another scale, this time composed of six items, derived from the CEI. Again there is a substantial effect favoring our experiential respondents $(p<.001)$.

In summary, what the data from Table 1 suggest is that persons who as adults report NDEs are not as children especially inclined toward 
involvement in a world of fantasy, but they are apparently already sensitive to nonordinary realities.

The question that now confronts us, however, is what factors might have been operative in the childhood histories of our experiential sample to make them so sensitive to these nonordinary realities?

This brings us to the second questionnaire in our battery, which we labeled somewhat neutrally the Home Environment Inventory.

Home Environment Inventory (HEI). The HEI was actually intended to be a measure of various components of childhood abuse and trauma since, as we have stated, in doing this study we sought to determine whether there might be any relationship between such childhood experiences and susceptibility to NDEs. Accordingly, we constructed this inventory so as to yield measures of childhood abuse and trauma of the following kinds:

1. physical abuse and punishment

2. psychological abuse

3. sexual abuse

4. neglect

5. negative home atmosphere

Table 2 reveals a most intriguing and disturbing pattern among these variables. As can be discerned from these data, there is a clearcut and consistent tendency for NDErs to report a greater incidence of childhood abuse and trauma. Indeed, statistically significant differences between experientials and controls emerge on all five components here, as shown by the probability figures given in the last column of the table.

Table 2

Means for Components of Childhood Abuse and Trauma from the Home Environment Inventory

\begin{tabular}{lccc}
\hline & $N D E(n=74)$ & $N D C(n=54)$ & $p$ \\
\hline Physical mistreatment & 8.48 & 6.24 & $<.02$ \\
Psychological abuse & 11.11 & 8.15 & $<.01$ \\
Sexual abuse & 4.82 & 2.77 & $<.05$ \\
Neglect & 6.22 & 4.26 & .005 \\
Negative home atmosphere & 17.02 & 11.63 & .002 \\
\hline
\end{tabular}


Because scores on these various components tended to be highly intercorrelated, we devised an overall index of childhood abuse and trauma based on all these measures combined. When we did so, we found that this composite index of childhood abuse and trauma again demonstrated a significant effect: NDErs scored much higher than controls $(p<.005)$.

Beyond the evidence from the HEI that experiential respondents have more stressful childhoods than controls, there are some additional data from the CEI that point in the same direction. In that questionnaire, we had also inquired into the incidence of serious and even life-threatening illnesses when our respondents were children.

In the light of our data from the HEI, our findings here are of no small interest: NDErs are much more likely to affirm that they were seriously ill as children ( $p<.001)$, suggesting that in this way, too, their childhoods were a source of greater stress to them than to our control respondents. Since six of our NDErs had their NDEs during childhood, a more valid analysis of this comparison would eliminate them. When childhood NDErs are excluded from this comparison, however, the effect still holds up ( $p=.0023$ ).

The overall results of our analyses of both the HEI and CEI, then, strongly support our earlier inference that one significant predisposing factor in the developmental history of our experiential respondents may well be the presence of relatively high levels of childhood abuse and trauma, and possibly other forms of stress, compared to our control group. The possible etiological role such incidents may play in the genesis of NDEs is a matter that can be considered properly only after a full presentation of our findings is complete. Therefore, we will defer its discussion until then.

However, since the factor of childhood abuse and trauma will prove to be a crucial link in the chain of our eventual interpretation, and also because it is obviously such a sensitive issue in its own right, it would be imprudent not to offer some cautionary statements concerning it here, and what the data from the Omega Project really can tell us about it.

First, it goes without saying that like all studies based on self-report data, this one can actually tell us nothing for certain concerning the childhood histories of our respondents, for of course we know only what they tell us. From our data alone we can never learn what in truth occurred in the lives of our respondents.

Second, what they tell us is that those of them who report NDEs also say they experienced more abuse and trauma as children. Does that mean, even assuming these self-reports are valid, that most or all such 
persons have such histories? Obviously, it does not. Indeed, exactly what proportion of our experiential and control respondents may be said to have a troubled childhood cannot be answered definitely from our analyses, but depends on arbitrary cutoff points for defining "significant abuse." Using one such criterion, we found that about 54 percent of our NDErs reported a "significant" amount of abuse and trauma, compared to about 30 percent of our control sample; but we would caution against giving much weight to such arbitrarily derived figures.

To repeat, all we can say here is that such reports are made more frequently by our experiential respondents.

Finally, though obvious, it still needs to be said that of course abuse and trauma in childhood isn't the only factor that may make for heightened sensitivity to nonordinary realities. Doubtless there are others, but they were not assessed in our study. They remain to be identified in future research. Child abuse and trauma, and other stressors, such as serious illness, may contribute to this kind of sensitivity, but this study doesn't establish that they have a primary, much less exclusive, role in this regard.

If it is indeed true that NDErs have endured more child abuse and trauma than controls, something else should follow. Exactly what that is we attempted to measure with the third instrument in our battery, which received the somewhat misleadingly bland and general title of Psychological Inventory.

Psychological Inventory (PI). This questionnaire, in fact, is far more specific in its focus than its innocuous label implies. Devised by Michael Wogan (in press), it is designed to measure tendencies toward psychological dissociation, and toward that end it has successfully been used in previous research by others (Sanders, McRoberts and Tollefson, 1989).

We employed this questionnaire in our investigation for two reasons: (1) to provide an indirect check on our supposition that NDErs might have a history of childhood abuse and trauma; and (2) to explore the possible role of dissociation in mediating access to nonordinary realities.

As to the first point, since it is known that persons with reputed histories of childhood abuse and trauma are more likely to score higher on measures of dissociation (Sanders, McRoberts and Tollefson, 1989; Sanders and Giolas, in press) or even, with extreme abuse, to develop serious dissociative disorders such as multiple personality (Kluft, 1985; Sachs, 1990), logically we should expect our NDErs to show 
elevated dissociation scores, too. Regarding the second point, since dissociation has been considered (e.g., Evans) conducive to alternate realities, and since NDErs seem especially sensitive to those realms, they can be expected on this basis also to score relatively high on our measure of dissociation.

It was, then, to test this prediction that the Wogan dissociation scale was included in our Battery. The outcome confirmed our expectation, as the mean score for the experiential group was 106.89 , as contrasted to a mean score of $\mathbf{9 5 . 8 2}$ for the control group.

A $t$ test shows that this difference is indeed significant $(p=.022)$. Furthermore, there is evidence from another study that the dissociation scores for the NDEr sample should be viewed as quite high compared to normal controls. Barbara Sanders, Gerald McRoberts and Christie Tollefson (1989) found that an unselected sample of 270 undergraduates at the University of Connecticut averaged only 91.90 on this same measure. That score is not significantly different from that of our own control group, but is markedly lower than that for our NDErs ( $p<$ .0001). Thus, there seems to be good support for the assumption that tendencies toward dissociation are indeed implicated in the psychological profile of NDErs.

\section{Aftereffects}

Three of the last four questionnaires in the Omega Project Battery were designed to explore possible changes in the aftermath of an NDE. In all three of these instruments respondents were asked to indicate how, if at all, they had changed since their experience or, for the control groups, since becoming interested in NDEs.

\section{Psychophysical Changes Inventory (PCI)}

On a statistical basis, the most striking differences, and perhaps the most thought-provoking, between our experiential and control respondents in this study appeared on our questionnaire dealing with psychophysical changes. We will present a number of specific examples of the kind of psychophysical changes we assessed in a moment, but an overall impression of these differences can first be grasped by inspecting each group's net psychophysical change scores. For the experiential group, the mean score was -1.78 , compared to a mean score of -30.67 for the control group. 
What these scores reflect is a very pronounced tendency for NDErs to aver that, relative to the control group, they underwent many more psychophysical changes following their experience. Indeed, the magnitude of the statistical difference between groups here is huge $(p<<$ .0001 ). An initial impression of the nature and range of these changes can be gleaned from Table 3 .

These data clearly indicate that, according to self-reports of our respondents, there are wide-ranging and powerful psychophysical changes following an NDE. These changes, which reflect a consistent array of highly significant differences between our experiential and control groups, span a spectrum from apparent biologically mediated effects through psychoenergetic and psychokinetic functioning to psychological states suggestive of expanded mental awareness. To be sure, the interpretation of our data on reported psychophysical changes is open to many possibilities, some of which we will comment on later, but for now it is enough to note that our findings here strongly imply that there are reliable, dramatic, and in many cases intriguing effects that appear to emerge in the aftermath of NDEs.

To illustrate just one of the provocative implications of this set of data, consider for a moment the findings listed in the last row of Table 3. These results indicate that our NDErs claimed significantly more often than controls that after their encounters they were more likely to cause electrical or electronic equipment (e.g., electric lights, digital watches, computers) to malfunction.

Now certainly most of us are aware that these claims are not rare, but perhaps relatively few people know that persons who make these claims repeatedly have now been studied (e.g., Shallis, 1988), and it turns out that many of their claims have been corroborated.

But more: the people who chronically have these problems, and who are now referred to as "electrical sensitives," tend to have certain traits in common. That is, it appears as if there is a coherent syndrome of electrical sensitivity. Its components are most interesting.

For one thing, electrical sensitives frequently have many allergies; about 70 percent of them have allergy problems, compared to about 15 percent in the population at large, according to Michael Shallis. They also report a very high incidence of psychic phenomena (again about 70 percent) and often claim to have "healing gifts." They seem abnormally sensitive to light and sound. Finally, they appear to be emotionally intense or labile individuals.

Why are these features of the electrical sensitivity syndrome so interesting? Though we knew nothing of Shallis's work when we designed our study, we happened to assess all of the above factors in our 


\section{Table 3}

Percent of Respondents Endorsing Items

on Psychophysical Changes Inventory

\begin{tabular}{|c|c|c|}
\hline & $N D E(n=74)$ & $N D C(n=54)$ \\
\hline \multicolumn{3}{|l|}{$\begin{array}{l}\text { Physical sensitivities } \\
\text { increase in: }\end{array}$} \\
\hline light sensitivity & 48.6 & 20.4 \\
\hline hearing sensitivity & 35.1 & 7.4 \\
\hline humidity sensitivity & 43.2 & 11.1 \\
\hline \multicolumn{3}{|l|}{ Physiological changes } \\
\hline metabolic rate & 17.6 & 9.3 \\
\hline body temperature & 17.6 & 7.4 \\
\hline blood pressure & 31.1 & 11.1 \\
\hline \multicolumn{3}{|l|}{ Neurological changes } \\
\hline difference in: & & \\
\hline nervous system & 51.4 & 18.5 \\
\hline brain structure & 36.5 & 7.7 \\
\hline \multicolumn{3}{|l|}{ Energetic changes } \\
\hline $\begin{array}{l}\text { increase in: } \\
\text { energy currents in body }\end{array}$ & 50.0 & 13.0 \\
\hline $\begin{array}{l}\text { decrease in: } \\
\text { sleep time }\end{array}$ & 39.2 & 16.7 \\
\hline \multicolumn{3}{|l|}{ Emotional changes } \\
\hline $\begin{array}{l}\text { increase in: } \\
\text { mood swings }\end{array}$ & 28.4 & 13.0 \\
\hline \multicolumn{3}{|l|}{ Expanded mental awareness } \\
\hline $\begin{array}{l}\text { increase in: } \\
\text { mind expansion }\end{array}$ & 58.1 & 27.8 \\
\hline information flooding & 48.6 & 20.4 \\
\hline \multicolumn{3}{|c|}{ Changes in paranormal functioning } \\
\hline psychic abilities & 60.8 & 31.5 \\
\hline causing electric or & & \\
\hline electronic malfunction & 24.3 & 7.4 \\
\hline
\end{tabular}


Psychophysical Changes Inventory for an entirely different set of reasons. As can be seen in Table 4, NDErs are anywhere from twice to four times as likely to claim that they are now characterized by these qualities. Thus, there appears to be something about these experiences that tends to move our NDErs in the direction of becoming an electrical sensitive.

One immediately thinks of the powerful experiences "in the light" reported by NDErs; and light, after all, is an electromagnetic phenomenon. One begins to wonder to what extent the pattern of psychophysical changes we have discovered may be mediated by electromagnetic effects, possibly causing a direct change in the respondent's measurable electrical field. If the psychophysical changes reported in connection with NDEs reflect some sort of psychobiological transformation, as our data strongly hint, might it be rooted in something as simple (and mysterious) as an electrical transmission of some kind?

These are admittedly extravagant speculations, but personal electrical fields can be measured in the laboratory (Valerie Hunt, personal communication, 1990; Hardt, 1990). It would be interesting if such measurements showed that the electrical fields of NDErs were distinctively different from those of normal controls.

Descending from the thin air of these speculative, though testable, musings to the hard ground of our data on psychophysical changes, there is one further set of findings that needs to be presented here since it bears directly on one possible interpretation of these effects.

Some of the changes delineated in Table 3 appear to fit into a syndrome that Western psychology has come increasingly to recognize as being entailed in certain forms of mystical experience and that is often associated with deep psychophysical perturbation. We are speaking of kundalini, which for our purposes here can simply, if inadequately, be described as a subtle form of bioenergy or prana, to use the word given to it in Yoga, that is said to be activated by the process of psychospiritual transformation (Krishna, 1971; White, 1979) and, these days, is more frequently mentioned in connection with what have come to be called "spiritual emergencies" (Bragdon, 1989; Grof and Grof, 1989).

Since there has already been speculation about the possible role of kundalini activation in NDEs (Ring, 1984; Greyson, 1990), we embedded a nine-item scale to assess this factor in our Psychophysical Changes Inventory. The net kundalini score for our experiential group was -1.04 , compared to a mean score of -6.22 for the control group, showing clearly that kundalini may be regarded as part of, and possibly underlying, the pattern of psychophysical changes we have already reported. 


\section{Table 4}

Percent of Subjects Endorsing Items Pertinent to the Electrical Sensitivity Syndrome

\begin{tabular}{lcc}
\hline & $N D E(n=74)$ & $N D C(n=54)$ \\
\hline More allergic & 24.3 & 7.4 \\
More psychic & 60.8 & 31.5 \\
Healing gifts & 41.9 & 11.1 \\
Sensitivity to light & 48.6 & 20.4 \\
Hearing acuity & 35.1 & 7.4 \\
Mood fluctuation & 28.4 & 13.0 \\
\hline
\end{tabular}

Again here, as in Table 3, it is the relative difference between the experiential and control groups that holds the key to the interpretation of these findings. That shows that kundalini activation is much more likely ( $p<<.0001$ ) to be reported afterward by NDErs than by controls. To appreciate the individual components of the kundalini syndrome, as measured by the kundalini scale of the PCI, consider the items listed in Table 5 along with their corresponding endorsement levels for our two groups.

Table 5 makes it clear that the kundalini effect is highly consistent across items as well as between groups. Whatever it may signify, it too is a definite part of the pattern of psychophysical changes reported by our NDErs and as such needs further study.

Life Changes Inventory (LCI) and Religious Beliefs Inventory (RBI). In addition to our inquiry into psychophysical changes, we were also interested to determine whether NDEs are associated with distinctive changes in personal values afterward. To evaluate such changes we used two separate instruments. The LCI was constructed so as to provide pre-/post- indices for a number of personal value domains. The RBI, on the other hand, was a twelve-item inventory that affords only a single score indicative of a shift toward universalistic spiritual values. Ring has discussed these two scales and their components elsewhere (1984).

Table 6 presents a summary of the principal personal value domains that the LCI measures. There are altogether nine such scales that can be derived from the LCI, all but one being composed of at least three items. The shift scores reported for each of the two groups are based on a five-point Likert scale ranging from -2 (strongly decreased) to +2 (strongly increased). Therefore, even apparently small net shifts can represent a sizable difference in terms of possible change, given the response range available. 
Table 5

Percent of Subjects Endorsing Items on the Kundalini Scale

\begin{tabular}{|c|c|c|}
\hline & $N D E(n=74)$ & $N D C(n=54)$ \\
\hline $\begin{array}{l}\text { I felt energy in my hands more } \\
\text { often than before. }\end{array}$ & 47.3 & 14.8 \\
\hline $\begin{array}{l}\text { I would sometimes feel a deep } \\
\text { ecstatic sensation, something like } \\
\text { an orgasm, for no reason. }\end{array}$ & 35.1 & 14.8 \\
\hline $\begin{array}{l}\text { I experienced severe or migraine } \\
\text { type headaches more often than } \\
\text { before. }\end{array}$ & 17.6 & 9.3 \\
\hline $\begin{array}{l}\text { I became aware of energy } \\
\text { discharges or currents flowing } \\
\text { through my body. }\end{array}$ & 50.0 & 13.0 \\
\hline $\begin{array}{l}\text { I would occasionally experience } \\
\text { sensations of tickling, itching, or } \\
\text { tingling on or underneath my } \\
\text { skin. }\end{array}$ & 39.2 & 3.7 \\
\hline $\begin{array}{l}\text { I became aware of internal lights } \\
\text { or colors. }\end{array}$ & 43.2 & 9.3 \\
\hline My hands often felt hot. & 33.8 & 11.1 \\
\hline $\begin{array}{l}\text { I would have sensations of extreme } \\
\text { heat or cold move through my } \\
\text { body more often than before. }\end{array}$ & 37.8 & 20.4 \\
\hline $\begin{array}{l}\text { My body would occasionally shake, } \\
\text { vibrate, or tremble for no } \\
\text { apparent reason. }\end{array}$ & 25.7 & 3.7 \\
\hline
\end{tabular}

Two statements will sum up the main trends to be discerned in Table 6: (1) in general, there is a statistically significant reported shift in the direction of increased altruism, social concern, and spirituality for both groups; and (2) in general, these changes are somewhat more pronounced for our experiential group and are significantly $(\mathrm{p}<.05)$ greater for the domains of appreciation for life, self-acceptance, and concern for others.

Certainly, the overall trend of these data on value shifts-and this, we think, is the main point to be grasped here-shows that individuals who have become involved in the world of NDEs, whether through 
Table 6

Net Value Shifts on the LCI

\begin{tabular}{lcc}
\hline Value Domain & $N D E(n=74)$ & $N D C(n=54)$ \\
\hline Appreciation for life & 1.33 & 1.02 \\
Self-acceptance & 1.13 & 0.80 \\
Concern for others & 1.21 & 0.92 \\
Concern for impressing others & -0.66 & -0.47 \\
Materialism & -0.58 & -0.39 \\
Concern with social/planetary & & \\
$\quad$ issues & 0.51 & 0.36 \\
Quest for meaning & 1.27 & 1.09 \\
Spirituality & 1.22 & 1.09 \\
Religiousness & 0.17 & 0.33 \\
\hline
\end{tabular}

personal experience or simply personal interest, tend to state that on the whole it has made a positive difference in their lives, if one is willing to grant that having a greater appreciation for life, oneself, others, and the world at large, are positive changes. That this is so despite the traumatic nature of the circumstances often associated with the onset of NDEs appears to be persuasive testimony to the transformative power of these experiences.

Of course, perhaps not everyone would be so swift to assert that all the changes on the LCI are positive. For example, the last row of values in Table 6 shows that NDEs have a negligible effect on religiousness, something that might come as a surprise, even a disappointment, to some readers. On the other hand, the row just above that shows that both NDEs and interest in such experiences are associated with strong perceived increases in spirituality, which again may please some while discontenting others.

However that may be, precisely this same pattern of a net movement toward spirituality, but not religiousness, was revealed through an analysis of our second measure of personal values, the RBI. To repeat, this instrument provides one overall score that signifies the extent to which an individual moves toward universalistic spiritual values as opposed to sectarian religious ones. To the extent that's so, the RBI gives a positive value, while a shift in the opposite direction would give a negative value. The mean RBI scores were 5.45 for the experiential group and 5.19 for the control group. 
What these values show is that a highly significant shift again occurs for both groups. Although there is a suggestion that NDErs shift more than the controls, this difference is not significant. As will be apparent, these findings dovetail nicely with the general pattern revealed by the analysis of the $\mathrm{LCI}$.

\section{Opinion Inventory (OI)}

The OI, the last questionnaire in our battery, was designed to provide information on the beliefs and worldviews of our respondents. In this case, however, our respondents were merely asked to express their agreement or disagreement with a set of thirty statements, or to register no opinion; thus they were not required as such to indicate whether their opinions had changed in light of their experiences or interests regarding NDEs. Nevertheless, since this questionnaire was filled out only after such experiences had occurred or such interests had developed, the OI may safely be regarded as a kind of post-test without a pre-test.

The OI assessed two principal domains of beliefs and worldviews of concern to us here: the possible evolutionary significance of NDEs and their possible purposive nature. Table 7 presents representative items from each of these two categories, along with the percentages of respondents agreeing and disagreeing with each belief. As noted above, some items were worded differently in alternate forms of the OI so as to be appropriate to experiential or control respondents. Those given in this and the next table are taken from the NDE battery.

As can easily be seen, there is widespread agreement in both groups with statements implying that we are in the midst of an evolutionary spurt toward greater spiritual awareness and higher consciousness, and that the occurrence of NDEs is an integral part of that progression. Although there are some differences between groups, their commonalities are impressive.

As to the question of a larger purpose behind the emergence of NDEs in our time, Table 8 provides a sampling of our respondents' opinions in this matter.

Here again the implications of our findings seem straightforward. First, it's clear that our respondents are inclined to agree that there are "higher forces" orchestrating these experiences and that they are meant to awaken individuals to the existence of a larger cosmic plan for life on earth. Not surprisingly, those who actually have had these experiences are somewhat more likely to endorse these statements 


\section{Table 7}

Percent of Subjects Agreeing and Disagreeing With "Evolutionary Items" On the Opinion Survey

\begin{tabular}{|c|c|c|c|}
\hline Item & & $(n=74)$ & $N D C(n=54)$ \\
\hline I believe that the changes & Agree & 54.1 & 55.6 \\
\hline $\begin{array}{l}\text { I've undergone since my NDE } \\
\text { are part of an evolutionary } \\
\text { unfolding of humanity. }\end{array}$ & Disagree & 16.2 & 14.8 \\
\hline $\begin{array}{l}\text { In my opinion, the wide- } \\
\text { spread occurrence of NDEs } \\
\text { is part of a larger plan to } \\
\text { promote the evolution of } \\
\text { consciousness on a species- } \\
\text { wide scale. }\end{array}$ & $\begin{array}{l}\text { Agree } \\
\text { Disagree }\end{array}$ & $\begin{array}{l}52.7 \\
14.9\end{array}$ & $\begin{array}{l}50.0 \\
13.0\end{array}$ \\
\hline $\begin{array}{l}\text { We are already in or at least } \\
\text { on the verge of a New Age. }\end{array}$ & $\begin{array}{l}\text { Agree } \\
\text { Disagree }\end{array}$ & $\begin{array}{l}67.6 \\
10.8\end{array}$ & $\begin{array}{r}53.7 \\
9.3\end{array}$ \\
\hline $\begin{array}{l}\text { Evolutionary forces are al- } \\
\text { ready at work which will } \\
\text { transform humanity at large } \\
\text { into a more self-aware, spiri- } \\
\text { tuality sensitive species. }\end{array}$ & $\begin{array}{l}\text { Agree } \\
\text { Disagree }\end{array}$ & $\begin{array}{r}59.5 \\
8.1\end{array}$ & $\begin{array}{l}38.9 \\
13.0\end{array}$ \\
\hline
\end{tabular}

Table 8

Percent of Subjects Agreeing and Disagreeing with "Purposiveness Items" On the Opinion Survey

\begin{tabular}{|c|c|c|c|}
\hline Item & & $(n=74)$ & $N D E(n=54)$ \\
\hline $\begin{array}{l}\text { I believe that my NDE was } \\
\text { "arranged" or "designed" by } \\
\text { a higher agency or by my } \\
\text { higher self. }\end{array}$ & $\begin{array}{l}\text { Agree } \\
\text { Disagree }\end{array}$ & $\begin{array}{l}63.5 \\
18.9\end{array}$ & $\begin{array}{l}44.4 \\
25.9\end{array}$ \\
\hline $\begin{array}{l}\text { I believe that my NDE oc- } \\
\text { curred so as to awaken me } \\
\text { to the existence of larger } \\
\text { cosmic forces which are af- } \\
\text { fecting our lives. }\end{array}$ & $\begin{array}{l}\text { Agree } \\
\text { Disagree }\end{array}$ & $\begin{array}{l}50.0 \\
20.3\end{array}$ & $\begin{array}{l}44.4 \\
22.2\end{array}$ \\
\hline $\begin{array}{l}\text { I feel I have a mission to } \\
\text { use what I have learned } \\
\text { from my NDE to spread } \\
\text { God's love to all. }\end{array}$ & $\begin{array}{l}\text { Agree } \\
\text { Disagree }\end{array}$ & $\begin{array}{l}58.1 \\
27.0\end{array}$ & $\begin{array}{l}50.0 \\
31.5\end{array}$ \\
\hline
\end{tabular}


than persons who have only an interest in them, but the overall trend of support for items of this kind is strong even for the control group. Second, it is equally clear that those who have had or become interested in NDEs are inclined to see a religious meaning in NDEs, specifically, to "spread God's love." If there is a "message" to the NDE, then from the standpoint of our respondents, this is it.

In summary, then, in the sphere of belief systems and worldviews, both groups tend to agree that NDEs reflect a purposive intelligence and that they are part of an accelerating evolutionary current that is propelling the human race toward higher consciousness and heightened spirituality. When we reflect on the pattern of psychophysical and value changes associated with NDEs, it is easy to see how these conclusions must inevitably be fostered by the aftereffects of these experiences themselves. In the context, the opinions of our respondents are perfectly consistent with the general trend of the other data presented in this section on aftereffects: whether we are discussing psychophysical changes, personal values, or beliefs and worldviews in the light of NDEs, they are all of a piece.

\section{Discussion}

\section{Psychological and developmental factors}

Our findings related to possible developmental antecedents of NDEs and to the mode of psychological functioning characteristic of those persons reporting such experiences appear to us to hang together quite neatly from a theoretical point of view. While this is only a preliminary survey from which it would be quite unwarranted to draw any causal inferences, we would nevertheless like to offer a possible framework for conceptualizing the nature of the relationships our data appear to disclose. As such, this framework could then serve as the basis for a testable hypothesis in subsequent research.

We begin by postulating that a history of child abuse and trauma plays a central etiological role in promoting sensitivity to NDEs. Our assumption, which reflects a now increasingly widespread understanding of some of the consequences of childhood abuse and trauma, is that growing up under such conditions would tend to stimulate the development of a dissociative response style as a means of psychological defense. Children who are exposed either to the threat or the actuality of physical violence, sexual abuse, or other severe traumata, will be strongly motivated selectively to "tune out" those aspects of their 
physical and social world that are likely to harm them by splitting themselves off from the sources of these threats, that is, by dissociating. By doing so, they are more likely thereby to "tune into" other, nonsensory realities where, by virtue of their dissociated state, they can feel safe regardless of what is happening to the body. In this way, as Evans (1989) has theorized, dissociation would be predicted to allow, in turn, relatively easy access to alternate, nonordinary realities.

When, in later life, such persons undergo the trauma of a near-death incident, they are thus more likely than others, because of their prior familiarity with nonordinary realities, to be able to "flip" into that state of consciousness, which, like a special lens, affords a direct glimpse of the NDE.

What we are suggesting, then, is that such persons are what we might call psychological sensitives with low stress thresholds, and that it is their traumatic childhoods that have helped to make them so. From our point of view, however, these individuals-our NDErs-are the unwitting beneficiaries of a kind of compensatory gift in return for the wounds they have incurred in growing up: that through the exigencies of their difficult childhoods they also come to develop an extended range of human perception beyond normally recognized limits. Thus, they may experience directly what the rest of us with unexceptional childhoods may only wonder at.

Such an interpretation, while necessarily speculative, does at least account for the pattern of relationships that appears to link child abuse and trauma, psychological dissociation, and sensitivity to nonordinary realities in a meaningful fashion. In any case, we hope it serves as a spur to others to carry out the careful and in-depth psychological studies necessary to establish whether it has validity and explanatory power.

\section{Aftereffects}

As our concluding comments on the OI implied, we find that in the realm of aftereffects, just as it was with our constellation of psychological and developmental factors, our results conform to a highly coherent pattern. Whether we examine the nature of the psychophysical changes our respondents report, their personal value shifts, or their opinions and worldviews, there is an impressive consistency in their assertions that their experiences of, or concern with, NDEs have changed them, often apparently quite radically, and largely in positive ways. Certainly, their answers to our questionnaires suggest that 
through their involvement with the world of NDEs, they have been expanded in their psychophysiological functioning, cognitive processes, and social values and made more hopeful concerning the outcome of humanity's evolution.

On the PCI, of course, the chief finding concerned the differences between NDEr and control respondents, which were statistically enormous. Overall, our PCI data suggested that experiencers believe that they have been profoundly affected psychologically, psychophysically, and presumably spiritually by the encounters they have undergone. The interpretative question we face here, however, is to try to understand what could be responsible for this undeniably provocative pattern of self-report data.

One could argue, of course, that it is something in the nature of these experiences themselves that induces these changes directly. We have already speculated about the possible role of electromagnetism in triggering some of these effects. But it is equally reasonable and perhaps more plausible to surmise that these changes are more likely to be more directly traceable to differences in the lifestyle afterward: changes in diet, meditation practices, or, perhaps more indirectly, the kind of groups people join or the reading they do. Without controlling for such factors, it is obviously impossible to draw any inferences concerning what may mediate these changes, assuming they are real and not merely subjective.

That last phrase brings up a cogent objection to these findings and points to an important limitation of this research. Obviously our selfreport data, being subjective, are no substitute for the kind of objective measurements that could be made in the laboratory. Our data as well as our previous interpretative comments strongly suggest that the step from survey research to laboratory investigation of persons who have had NDEs would be well warranted. Indeed, we hope that our findings on possible psychophysical changes here will have provided enough prima facie data to encourage qualified investigators to continue the search for these effects in the laboratory. Without such research, our findings must remain intriguing but inconclusive; with it, we may be more certain whether these extraordinary claims made by our NDErs are based in fact or are merely fancy.

When we consider the data from the LCI and RBI, however, we must remember that here it is the overall similarity between our experiential and control respondents that was most striking. In its own way, this finding is quite remarkable because our control group was made up of persons who have had a very different kind of developmental history than our experiential respondents, have no particular affinity 
for states of consciousness disclosing alternate realities or propensities for dissociative thinking, and certainly don't report anything like the profound psychophysical changes that characterize our experientials. Yet, when it comes to the expression of personal values, these individuals seem to view the world in much the same way as do our NDErs, as though they are seeing it essentially through the same eyes. This suggests that, whereas having NDEs may promote the kind of value shifts the LCI and RBI disclose, merely becoming interested in these phenomena may also accomplish the same end. To sort out the relative influence here of personal experience versus social contagion is not possible from our data alone, but our findings do suggest that this would be a most worthwhile task for the social psychologist and sociologist interested in social movements.

Although the overall similarity between our experiential and control groups was perhaps the most important result deriving from the LCI and RBI, there were of course some differences, too. As previously noted, though both experiential and control subjects tend to move toward more prosocial and universalistic values, this trend was on the whole somewhat stronger for our experiential respondents, suggesting that the personal experience factor may give an added impetus to such changes.

One question that can be raised concerning all the aftereffects so far discussed is how durable these changes are. Do they, for example, persist for some time and then revert to previous levels or do they tend to endure? To explore this matter in a preliminary way, we performed some analyses in which we divided our experiential sample into four groups according to how much time had elapsed since their encounter. The first had had their NDE within the past five years; the second, between six and fifteen years ago; the third, sixteen to thirty years, and the fourth, more than thirty years ago. Using this classification, we examined psychophysical changes using our total score index and two value domain scales, concern for others and spirituality. Our findings for all three analyses were identical: there were no differences among groups, indicating that, at least for the aftereffects we assessed, they tend to be maximal within five years and stable over time. Thus, our data here are consistent with the inference that the aftereffects in our study are not transient changes but represent persisting traits.

Finally, to return once more to the OI, here again it was the similarity between both of our groups of respondents that was noteworthy. Our sample as a whole appears to regard NDEs positively and believes that they hold potential benefits for humanity that we can hardly conceive of today. In interpreting these findings, we face the same 
problem we have encountered before: it is impossible to know how much these opinions are shaped by direct personal experience, how much through social influence processes within the NDE community, and how much through the operation of the zeitgeist with its apocalyptic imagery and expectations. All we can say here is that the general belief system represented by the body of our findings on the OI is entirely in keeping with our pattern of aftereffects and therefore may simply be their cognitive aspect. Only further research that directly focuses on sources of beliefs in the NDE community can hope to clarify how these opinions come to be formed and how they are maintained.

\section{Implications and Conclusions}

\section{The NDE-Prone Personality}

We began with the question of whether some distinctive psychological factors predispose some people to remember NDEs, and in our search for an answer we were led, first by theory and eventually by data, to the concept of the NDE-prone personality. It is this distinctive personality type, we believe, that furnishes the clue that NDE researchers have been looking for in their attempts to fathom the mystery of selective recall of NDEs.

What, then, is the core defining feature of the NDE-prone personality? In our judgment, it is the capacity to shift into states of consciousness that afford access to nonordinary realities coupled with strong tendencies toward psychological absorption. That is, the person who is especially likely to register and recall an NDE is one whose awareness is easily able to transcend the sensory world and enter into focused attention to interior states. Once the shift to non-sensory realities has occurred, it seems to be the capacity for psychological absorption that is crucial.

For example, Peter Nelson (1989), in a recent study of predictors of mystical and visionary experiences, found that psychological absorption was the single most important personality variable he measured and that it was in fact linearly related to frequency of such experiences. Nelson's findings concerning the role of psychological absorption are perfectly congruent with other studies of the correlates of mystical experience (Mathes, 1982; Spanos and Moretti, 1988) as well as with Harvey Irwin's work on out-of-body experiences, facility for which also seems to be related to absorption tendencies. 
Furthermore, in the specific context of NDEs, we need to recall Council and Greyson's pioneering study (1985) that likewise found a relationship between absorption and NDE status. Finally, our own data from the Omega Project, especially those having to do with pronounced sensitivities to alternate and psychic realities on the part of NDErs, can easily be subsumed by the larger construct of psychological absorption. This, then, seems to be the conceptual center of what we have here called the NDE-prone personality.

To prevent any misunderstanding here, we need to emphasize that by pointing to the centrality of psychological absorption and the utility of the concept of the NDE-prone personality for the understanding of NDEs, we do not at all mean to "psychologize" the NDE or to suggest that its spiritual significance is somehow called into question by our theoretical perspective. Similarly, by discovering the role that child abuse and trauma apparently play in promoting sensitivity to NDEs, we do not intend to "pathologize" the NDE or denigrate individuals who report such experiences. Indeed, anyone who is already familiar with our previous work on NDEs will know that we have long endorsed the spiritual authenticity of NDEs and have been supportive of NDErs and organizations that serve them. Nothing we have found here has altered our position or stance toward NDErs. Thus, by focusing on some of the antecedents that predict NDE status, we have only tried to answer some persisting questions about the psychological profile of the NDEr; the mystery and numinous power of the NDE itself remains intact and in our judgment at least is unlikely ever to be fully explained by psychological or scientific concepts. Similarly, it is important to keep in mind that childhood abuse and trauma is only one route, and the only one we happened to investigate here, that leads to the development of the NDE-prone personality. Doubtless, some people are simply born more psychologically sensitive than others while still others may be encouraged through positive means, such as their parents stimulating imaginative involvement in childhood, to cultivate their sensitivity to nonordinary realities. In short, there are likely to be many different and diverse factors associated with the emergence of NDE-prone personalities. Future research will, we trust, help us to see these more clearly and will give us a more rounded picture of how the NDE-prone personality is shaped.

All this said, however, there is still another kind of justification we must give in defense of our psychological approach here. That stems from the recognition that the NDE-prone personality is only half of the story of the Omega Project. 


\section{The Omega Prototype}

If one concentrates on the antecedents of the NDE, as we have done so far, one naturally tends to look at the development of what we have called an NDE-prone personality. But when one recalls that this study was also concerned with the aftereffects of NDEs, one realizes that from that perspective one sees something else: the emergence of what appears to be a more highly evolved human being that Greyson (1990) has called the Omega Prototype.

In dealing with the Omega Prototype, we are no longer fixated on how the NDE-prone personality may have been fashioned from a complex matrix of genetic and social influences, but rather with what has been created directly out of the crucible of the NDE itself. What leads up to the NDE may be very different from what the NDE leads to. Hardship may have preceded the NDE, trauma may accompany it, but, judging from our research, human transformation seems to be the fruit of its womb.

The idea that the NDE is a transformative experience is hardly new; indeed by now it has nearly the status of a received truth in the literature on NDEs. But here we are talking about, and finally have some evidence for, a kind of transformation that goes beyond a mere change in values and outlook. Our data suggest that this transformation is in fact psychophysical, that NDErs, through their experience, undergo certain changes that affect their physiological functioning, nervous system and brain, and mental processes so as to permit a higher level of human nature to manifest. Our findings on the apparent relationship between NDEs and kundalini activation are both representative and metaphoric of the seed potential of NDEs: a latent energy, which is held by kundalini theorists to transform the nervous system and promote the spiritual evolution of humanity, seems to be released by NDEs and through NDErs into the world. If NDEs are truly catalysts for human evolution, as we have argued (Ring, 1984), and as the majority of our NDE sample also hold, then the Omega Project may have provided us with the first preliminary evidence that its basis is an actual psychophysical transformation of the body (Thompson, 1989).

Of course, we are still a very long way from being able to make such claims with finality. Nevertheless, though we lack proof, we are at least and at last beginning to gather some evidence in support of this proposition. And our own suggestive findings here do not stand alone. Recently, for example, Greyson (1990) has summarized his data on 
kundalini and NDEs and has reported findings similar to our own. In addition, testimonies by individual NDErs, such as Barbara Harris (1990), represent important qualitative evidence that help both to corroborate and personalize the purely statistical information that we and Greyson have thus far presented.

Needless to say, from the standpoint of research we are still at the very beginning. As we have already indicated, we second Greyson's (1990) call for laboratory research in order to document the claims of NDErs as well as to provide further objective data on the psychophysical transformations that NDEs appear to induce. We also need more indepth psychological studies and case histories of NDErs so that we can better appreciate the nature, dynamics, and development of the NDEprone personality. Both types of investigations are necessary if we wish more fully to understand the roots of the NDE-prone personality as well as the fruits of the NDE itself-and possibly our own human future-the Omega Prototype.

\section{References}

Atwater, P.M.H. (1988). Coming back to life: The after-effects of the near-death experience. New York, NY: Dodd, Mead.

Bragdon, E. (1988). A sourcebook for helping people in spiritual emergency. Apton, CA: Lightening Up Press.

Bush, N. (1983). The near-death experience in children: Shades of the prison-house reopening. Anabiosis: The Journal of Near-Death Studies, 3, 177-193.

Council, J.B., and Greyson, B. (1985). Near-death experiences and the "fantasy-prone" personality: Preliminary findings. Paper presented to the American Psychological Association 93rd Annual Convention, Los Angeles, CA.

Evans, H. (1989). Alternate states of consciousness. Wellingborough, England: Aquarian Press.

Flynn, C.P. (1986). After the beyond: Human transformation and the near-death experience. Englewood Cliffs, NJ: Prentice-Hall.

Gallup, G., Jr. (1982). Adventures in immortality: A look beyond the threshold of death. New York, NY: McGraw-Hill.

Grey, M. (1985). Return from death: An exploration of the near-death experience. London, England: Arkana.

Greyson, B. (1983). Increase in psychic phenomena following near-death experiences. Theta, 11, 26-29.

Greyson, B. (1990). Scientific commentary. In B. Harris and L. Bascom Full Circle: The near-death experience and beyond (pp. 251-270). New York, NY: Pocket Books.

Grof, S., and Grof, C. (Eds.). (1989). Spiritual emergency: When personal transformation becomes a crisis. Los Angeles, CA: J.P. Tarcher.

Hardt, J. (1990). Kundalini and biofeedback. Paper presented to the First International Conference on Energies of Transformation, Asilomar, CA.

Harris, B., and Bascom, L. (1990). Full circle: The near-death experience and beyond New York, NY: Pocket Books.

Irwin, H.J. (1985). Flight of mind: A psychological study of the out-of-body experience. Metuchen, NJ: Scarecrow Press. 
Kluft, R.P. (Ed.). (1985). Childhood antecedents of multiple personality. Washington, DC: American Psychological Association.

Kohr, R.L. (1983). Near-death experiences, altered states, and psi sensitivity. Anabiosis: The Journal of Near-Death Studies, 3, 157-176.

Krishna, G. (1971). Kundalini: The evolutionary energy in man. Berkeley, CA: Shambhala.

Mathes, E.W. (1982). Mystical experiences, romantic love, and hypnotic susceptibility. Psychological Reports, 50, 701-702.

Morse, M.L., Castillo, P., Venecia, D., Milstein, J., and Tyler, D. (1986). Childhood neardeath experiences. American Journal of Diseases of Children, 140, 1110-1113.

Nelson, P.L. (1989). Personality factors in the frequency of reported spontaneous preternatural experiences. Journal of Transpersonal Psychology, 21, 193-209.

Osis, K., and Haraldsson, E. (1977). At the hour of death. New York, NY: Avon.

Pennachio, J. (1988). Near-death experiences and self-transformation. Journal of NearDeath Studies, 6, 162-168.

Ring, K. (1980). Life at death: A scientific investigation of the near-death experience. New York, NY: Coward, McCann and Geoghegan.

Ring, K. (1984). Heading toward omega: In search of the meaning of the near-death experience. New York, NY: William Morrow.

Ring, K. (in press). Near-death experiences, imaginal worlds, and light after death. In G. Doore (Ed.), What survives? Los Angeles, CA: J.P. Tarcher.

Sabom, M.B. (1982). Recollections of death: A medical investigation. New York, NY: Harper and Row.

Sachs, R. (1990). A comparison of experienced anomalous trauma and Satanic cult experiences. Paper presented to the Second Conference on Treatment and Research on Experienced Anomalous Trauma, Blacksburg, VA.

Sanders, B., McRoberts, J., and Tollefson, C. (1989). Correlates of dissociation in a college population. Journal of Dissociation, 2, 17-23.

Sanders, B., and Giolas, M. (in press). Dissociation and child abuse in disturbed adolescents. American Journal of Psychiatry.

Shallis, M. (1989). The electric connection: Its effects on mind and body. New York, NY: New Amsterdam.

Spanos, N.P., and Moretti, P. (1988). Correlates of mystical and diabolical experiences in a sample of female college students. Journal for the Scientific Study of Religion, 27, 105-116.

Stewart, S., and Carrione, M.L. (1987). The chosen few. Unpublished term paper, Advanced Seminar in Near-Death Studies, University of Connecticut, Storrs, CT.

Sutherland, C. (1990). Psychic phenomena following near-death experiences: An Australian study. Journal of Near-Death Studies, 8, 93-102.

Thompson, K. (1989). The future of the body. Yoga Journal, 86. 38-45.

White, J. (Ed.). (1979). Kundalini, evolution and enlightenment. New York, NY: Anchor Books.

Wilson, S.C., and Barber, T.X. (1983). The fantasy-prone personality: Implications for understanding imagery, hypnosis, and parapsychological phenomena. In A. Sheikh (Ed.), Imagery: Current theory, research, and application (pp. 340-387). New York, NY: John Wiley.

Wogan, M. (in press). A new test for dissociation. Journal of Experimental and Clinical Hypnosis. 